\title{
Philosophy of Interactive e-Learning for Power Electronics and Electrical Drives: a Way from Ideas to Realization
}

\author{
Pavol Bauer ${ }^{\dagger}$ and Viliam Fedak* \\ $\dagger$ Dept. of Electrical Sustainable Energy, Delft University of Technology, Delft, The Netherlands \\ * Dept. of Electrical Eng. and Mechatronics, Technical University of Kosice, Kosice, Slovak Republic
}

\begin{abstract}
The paper reports about methodology at design of interactive e-learning modules that are suitable both for teaching and learning. They cover special topics of electrical engineering, starting from the fundamentals, through electrical machines, power electronics to the fields of controlled electromechanical energy conversion, like electrical drives, complex drive systems, application of drives, mechatronic systems, telemanipulation, and robotics. In the paper, the emphasis is devoted in detail to philosophy and realization of the modules from fields of Power Electronics and Electrical Drives. On several examples there are explained main principles and specialties at their development.
\end{abstract}

Key Words: e-Learning, Education, Electrical Drives, Interactive Simulations, Power Electronics

\section{INTRODUCTION}

Education in Power Electronics and Electrical Drives is enough daunting for students due to difficulties at proper description complexity of physical phenomena, understanding the circuit operation and complicated mathematical description. Understanding of new matters requires a high level of imagination. The traditional learning and training methods are not able to cope with demand of easy understanding the matter. The advances in information technology have reflected themselves in development of modern education methodologies. The e-learning methods help to improve understanding complex matters at saving time needed for their understanding, learning and following training.

In last years many efforts were made to develop multimedia web-based education modules. Several educational projects dealing with development of series of modules are known. The pioneering work with this respect was done by Johann Kolar [1], [2] and followed by many others in [7]-[21]. In the framework of the EU Leonardo da Vinci program, a welldesigned concept, clear methodology, application of carefully selected software programs and a European-wide co-operation has finished up in development of a set of courses on general and some special topics of applied electrical engineering [3]. In framework of the project 18 e-learning modules with interactive features and in a unified environment were developed.

\footnotetext{
Manuscript received May 17, 2010; revised Jul. 21, 2010

$\uparrow$ Corresponding Author: viliam.fedak@tuke.sk

Tel: +421-556022278, Fax: +421-55630115, Delft Univ, of Tech.

* Dept. of Electrical Eng. and Mechatronics, Technical University of Kosice, Slovak Republic
}

Their main philosophy was reported in [4], [5]. The modules are intended both for live presentation (lectures) and for web-based distant learning, including in-detail explanation for repetition and self-learning. They contain animations and interactive simulations allowing parameter changes while observing response. In the following experiences with the design of the modules are reported.

\section{Features of Power Electronics and Electrical DRIVES SUBJECTS}

At teaching of Power Electronics and Electrical Drives subjects the phenomena of various subsistence and complexity are to be explained. The learner has to understand principles of activity of non-visible phenomena (electrostatic, magnetic, electric, electromagnetic, and thermal fields) and directly nonvisible quantities (such as current, voltage, magnetic flux). Moreover, the electrical devices and circuits deal with rather abstract notions such as resistance, capacitance, inductance, etc.

This abstractness imposes high requirements on the learner for understanding behavior and mutual influence of the complicated phenomena. If the student does not understand the basic principles and fundamental laws of electrical engineering and behavior of basic subsystems in detail, he usually fails at learning more advanced topics such as electrical drives, complex circuits of power electronics, interaction of drives and electrical energy converters up to understanding of behavior of complex mechatronic systems. He might lose his interest about the matter, or he learns the matters only by heart without understanding the mutual consequences of the phenomena. 
Therefore, he is unable to apply his knowledge fully, especially if the conditions, devices or circuits are modified. Consequently, from the overview it can be derived that one of the key elements of successful teaching is to present the matter to be learned by a very visual and graphic way in clear steps marked out by high attractiveness.

\section{Philosophy of the Modules}

The electrical quantities and phenomena are not observable directly but they can be made observable (visible) by measuring. Explaining the phenomena, the teacher is assisted by various auxiliary aids in order to make them visible. The problem of the teaching concentrates itself to preparation of teaching material. The design of such material is a difficult task, even much more difficult than writing a textbook: the designer ought to have not only a good knowledge about the matter but he must be a good designer with artistic feeling, too. He should have in mind especially an overall attractiveness of the learning module.

At designing the screens, the developer has to take into consideration several principles:

- a clear idea that has to be taught,

- choice of basic elements to be explained (drawings, texts, equations),

- their balanced layout across the screen,

- design of suitable animations expressing the phenomena to be explained,

- use of unified colors and symbols that contribute to easier understanding.

A well organized teaching material has to allow performing small simulation experiments without necessity to switch between the learning module and a special simulation program. The interactivity has to be applied also in case of steady-state diagrams where the values of the parameters are changed by sliders.

Preparation of the modules presents a time-and-money consuming work and that is the reason why the design of the modules has to be performed efficiently and their utilization opportunities should be manifold. To satisfy requirements, we have accepted the philosophy of multiply utilization of the modules, i.e. the modules should be used both for teaching and for (self)learning. It means, the screens for teaching/lecturing (the main screens) give basic explanation of the presented matter and they contain animations and simulation schemes. They are linked with the screens for the learning (self-learning) giving in-depth the information and background - the second ones contain full information about the matter, derivation of equations, detailed description of the phenomena, etc.

The accepted solution supports both types of education (teaching and learning) and it also satisfies criteria for the blended learning. The student can watch both kinds of the screens what enables him to follow the step-by step explanation and/or perform small experiments (simulation, calculation, etc.). Moreover, the linked screen offers also other kind of information - like Questions to Review, etc.

Fig. 1 shows an example of a simple animated main screen to demonstrate the torque needed for the motor driving a car at

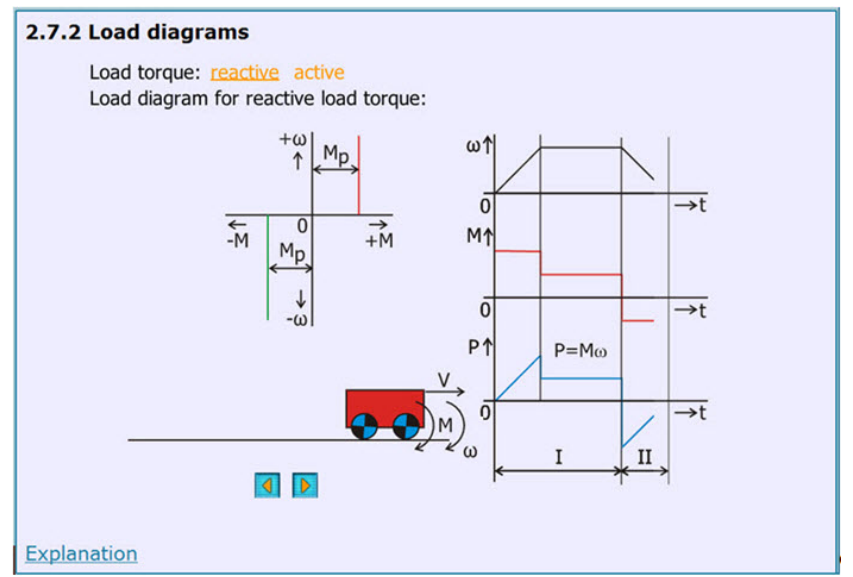

Fig. 1. Example of a primary screen in the unified environment (used for lecturing).

starting, steady state operation and braking. Each main screen has a linked screen giving full information about the matter on main screen and some other examples.

\section{EXAMPLES OF THE "INETELE" MODUleS}

Based on the described principles for e-learning modules a set of e-learning modules was developed that cover a wide area of electrical engineering and are arranged into five groups:

A. Fundamentals of Electrical Engineering

B. Electrical Machines

C. Electronics and Power Electronics

D. Electro-Mechanical Systems, Motion Control, and Mechatronics

E. CAD and Applied $S W$ in Electrical Engineering

\section{A. Group of Electrical Engineering Fundamentals}

In the first group of Electrical Engineering Fundamentals there are two essential basic modules:

1.1 Fundamentals of Electrical Engineering

1.2 Electrical Measurement Methodology

Both modules provide introduction into electrical engineering. As they are outside the scope of the paper we are not going into details here.

\section{B. Group of Modules on Electrical Machines}

This group involves the modules dealing with principles of static electrical machines (transformers) and rotating ones (motors, generators) based on application of electromagnetic laws. Four modules are in the group:

2.1 Basic Principles of Electrical Machines

2.2 Transformers

2.3 DC Machines

2.4 AC Machines

The learner has to learn not only the principles of operation of the electrical machines but also their construction. To satisfy this idea, the modules also shown the real machines, details and principles of their construction. Animations in the modules show structure and principles of operation of electrical 


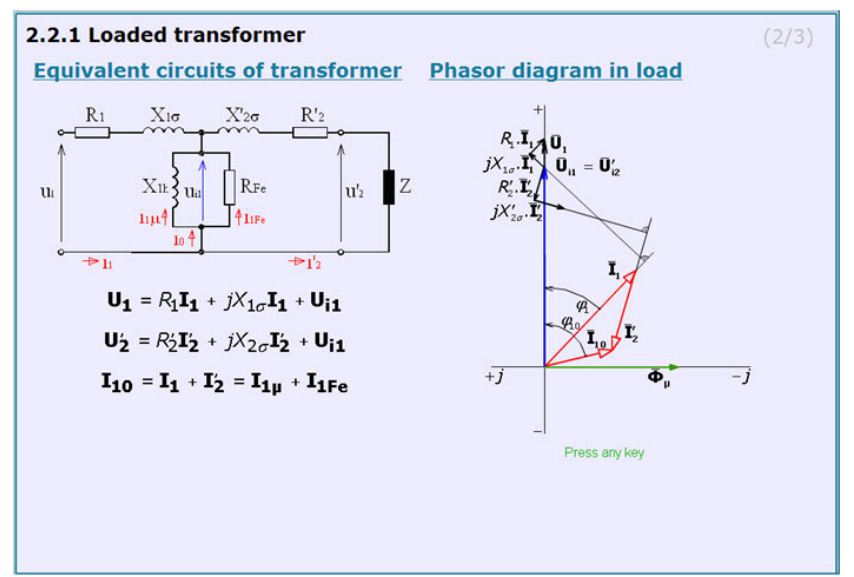

(a)

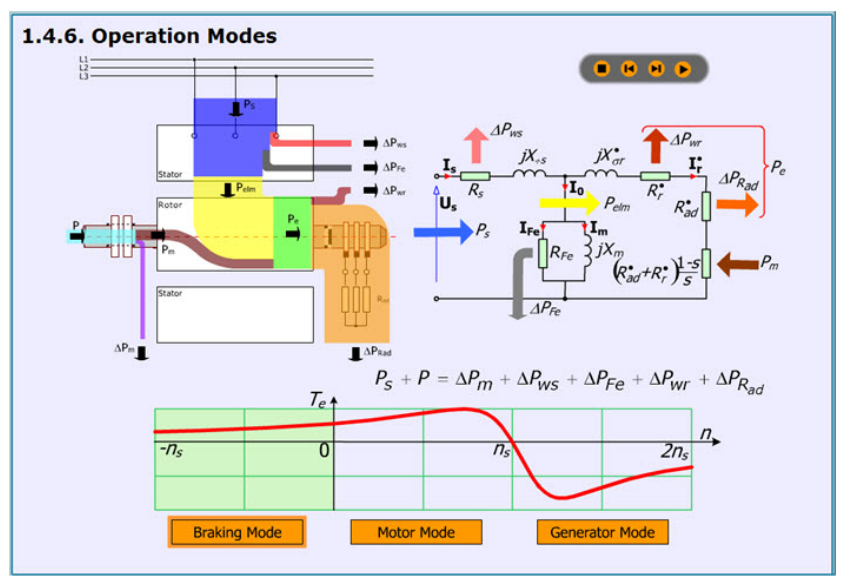

(b)

Fig. 2. Electrical Machines: (a) successive development of the phasor diagram of one-phase transformer circuit, (b) one-phase equivalent circuit of an induction machine explaining losses in the machine.

machines of various types (static, DC and AC rotating ones, both asynchronous and synchronous ones).

For illustration, Fig. 2(a) shows an example of a loaded transform equivalent circuit [22].

The complicated graph construction can be explained simply in steps: the appropriate voltage (current) vector of the transformer equivalent circuit is drawn after pushing any key and simultaneously, the appropriate voltage (current) is shown in the circuit across the device. Such visual animation considerably helps to understand principles at construction of the vector graphs.

Another example using the same principle is shown in Fig. 2(b), [24]. Here the balance of active power and losses in the asynchronous motor in the steady-state are explained at electromechanical conversion of the energy from the supply network into the mechanical power. The colors are used here to make at a glance the distinction among various power components and the appropriate device in the equivalent motor circuit where the power loss occurs. The power flow and/or loss in the device are lighted (and explained) successively - in the steps like they appear in the electrical machine. The steps are activated by pushing the step button.

When comparing the both figures, the b) solution enables to return the step backward but on the other side, it is sometimes advantageous, when the lecturer pushes any key instead to concentrate himself to find and push the exact button.

\section{Group of Modules on Electronics and Power Electronics}

The modules of this group deal with different aspects of power electronics starting with components, proceeding with control of power electronics and different issues related to power electronics and finishing with their applications.

The following modules are in this group:

3.1 Practical Electronics

3.2 Power Semiconductor Devices

3.3 Power Electronics

3.4 Control in Power Electronics

3.5 Power Electronic Applications in Electrical Power Systems

3.6 Harmonic Treatment in Industrial Power Systems

3.7 Electromagnetic Compatibility

The main issues can be summarized as explanation of:

- behavior of basic electronic and power electronics switching devices,

- behavior of complex electronic circuits,

- behavior of power electronic circuits of various complexity,

- power electronics in different applications.

When studying a certain power electronic circuit, the first question of the student always concentrates to different current paths in dependency of the switching states and certain impressed currents and voltages. With traditional teaching the current paths are drawn using different colors into some figures of the power circuit, or the teacher presents a slide-show in the classroom. Here, the approach of interactive animations is used. Different visualization principles for explaining power electronic circuits are summarized in [9].

To illustrate the ideas mentioned above, two examples from the module 3.5 Power Electronic Applications in Electrical Power Systems are shown. In the chapter of high power electronics several topologies used for high power are explained (Fig. 3a, b). The square wave generation principle shown there is a basic switching strategy used for high power converters. Detailed explanation of the circuit behavior is contained in the associated secondary screen. The continuously running animation was replaced by a static one where the cursor (orange vertical line in the time diagram) can be shifted in time by the lecturer.

This solution gives a possibility to explain circuit behavior given by switching states of the power semiconductor devices in the required time instant.

The voltage source inverter (Fig. 3(a)) generates square waves of phase voltages. The switches operate with 180 degrees conduction in one phase leg. Here two interactive screens are shown for illustration. The first time function (Fig. 3(a)) shows the state of switches (1-6, on-off), the second one shows the potential of the phase $A$ to neutral point $\mathrm{N}\left(\mathrm{V}_{\mathrm{AN}}\right)$ and phase $B$ to the neutral point $N\left(V_{A N}\right)$. The fourth one shows the potential of the phase $A$ to neutral point $n\left(V_{A N}\right)$ and the fifth time function shows phase $B$ to the neutral point $n\left(V_{A N}\right)$. The last time function shows the line to line voltage $\left(V_{\mathrm{AB}}\right)$. 


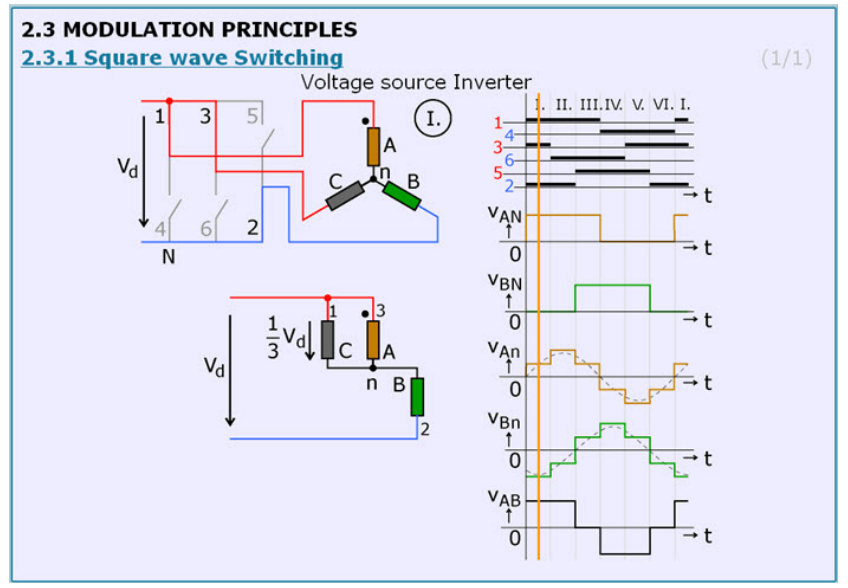

(a)

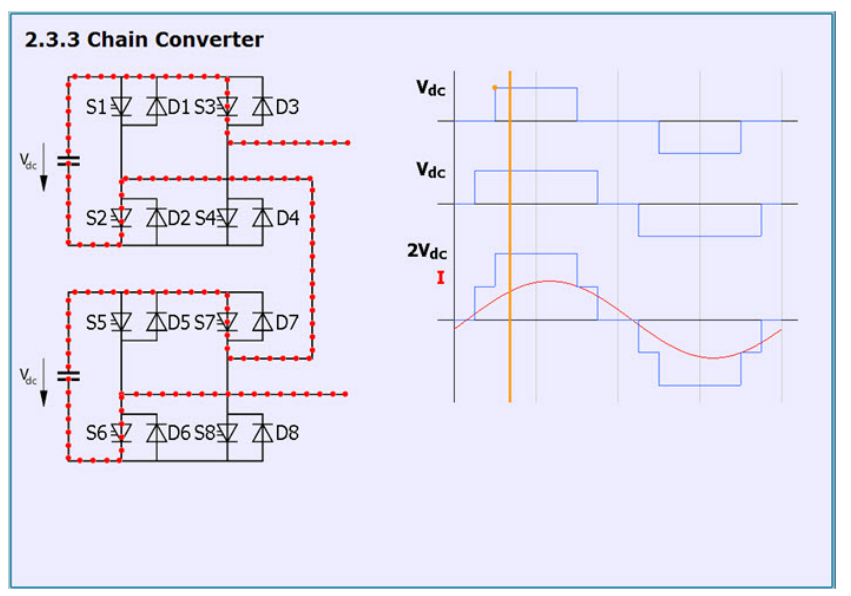

(b)

Fig. 3. Switching states demonstration in the power electronics converters: (a) square wave switching of the voltage source inverter; (b) a single-phase structure of an m-level cascade inverter.

The switches are always in the position corresponding to the position of the orange bar. The input voltage amplitude $\mathrm{Vd}$ is usually controllable here. The square wave is also obtained for sufficiently large values of modulation index, because the PWM degenerates into square wave operation. Therefore at any instant of time, three switches are on.

In the cascaded inverter, or so-called "chain circuit" approach, each pole is composed of a number of complete single-phase, voltage sourced " $H$-bridge" converters, each with its own isolated DC capacitor, as illustrated in Fig. 3(b). Here the moving dots shows the current path and switching states can be changed by sliding the orange bar (cursor) or changing the pulse width by moving the orange dot. One multilevel converter topology incorporates cascaded singlephase H-bridges with separate DC sources. Fig. 3b shows a single-phase structure of an $m$-level cascade inverter (with $\mathrm{m}=5$ ). The DC source is connected to a single-phase fullbridge, or H-bridge, inverter. Each inverter level can generate three different voltage outputs, $+\mathrm{V}_{\mathrm{DC}}, 0$, and an $-\mathrm{V}_{\mathrm{DC}}$ by connecting the DC source to the AC output by different combinations of the four switches, $S_{1}, S_{2}, S_{3}$ and $S_{4}$. To obtain $+\mathrm{VDC}$, switches $S_{3}$ and $S_{2}$ are turned on. By turning on the switches $S_{1}$ and $S_{4}$ yields voltage $-\mathrm{V}_{D C}$. By turning on $S_{1}$ and

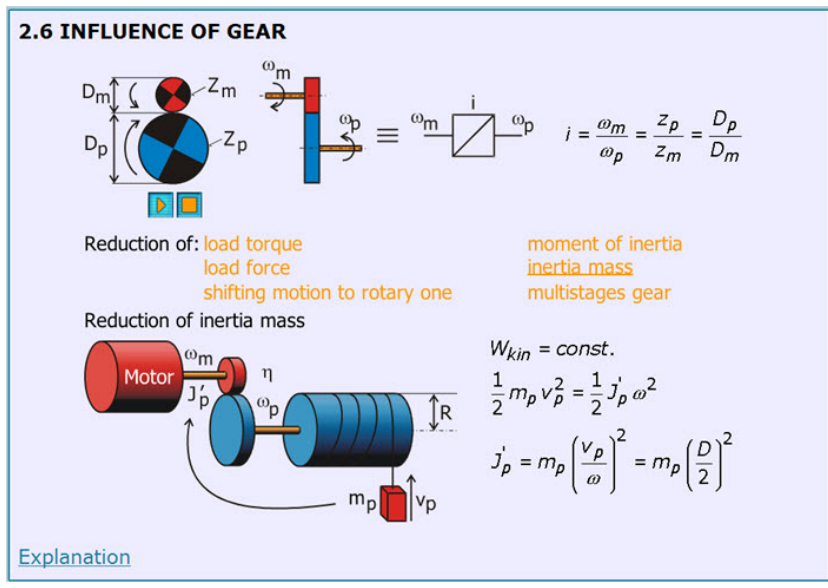

Fig. 4. Influence of the gear in the drive.

$S_{3}$ or $S_{2}$ and $S_{4}$, the output voltage is 0 . The conduction angle of the first pulse is changeable be moving the cursor.

\section{Group of Modules on Electro-Mechanical Systems, Motion Control, and Mechatronics}

Various applied modules are in this group that deal with transformation of the electrical energy into the mechanical form by electrical drives and with its control. The modules deal with:

- enlightenment of principles electromechanical conversion of energy,

- explanation of interactivity between electrical and mechanical circuits,

- description of ways of control the energy flow,

- setting up the mathematical models of the mechanical parts of drive systems,

- typical applications of drive systems.

Except of knowledge from electrical engineering also knowledge from mechanical engineering and control theory is required. The following modules are involved in the group:

4.1 Electrical Drives

4.2 Controlled Electrical Drives

4.3 Motion Control

4.4 Automotive Electrical Systems

4.5 Mechatronic Systems

4.6 Telematic Systems and Robotics

From view of the user it is important to manage easy the activities on the screen. For fast orientation of the user it is advisable to introduce a system of colors, e.g. to use the orange color for the letters, symbols, lines, devices, subsystems, etc., what enables user to easy orientate himself on the screen and to start a required action. In Fig. 4 (taken from the module of Electrical Drives) one can easy see the influence of the gear to reduction of motor torque, moment of inertia, to see influence of the multistage gear, etc.

The chosen activities are called simple by clicking to the chosen text. The module itself introduces fundamentals of electrical drives (drive mechanics, heating, dimensioning, methods of starting and braking) up to open-loop behavior of the system: motor - converter. Such system is shown in Fig. 5 and presents starting of an asynchronous motor supplied by 


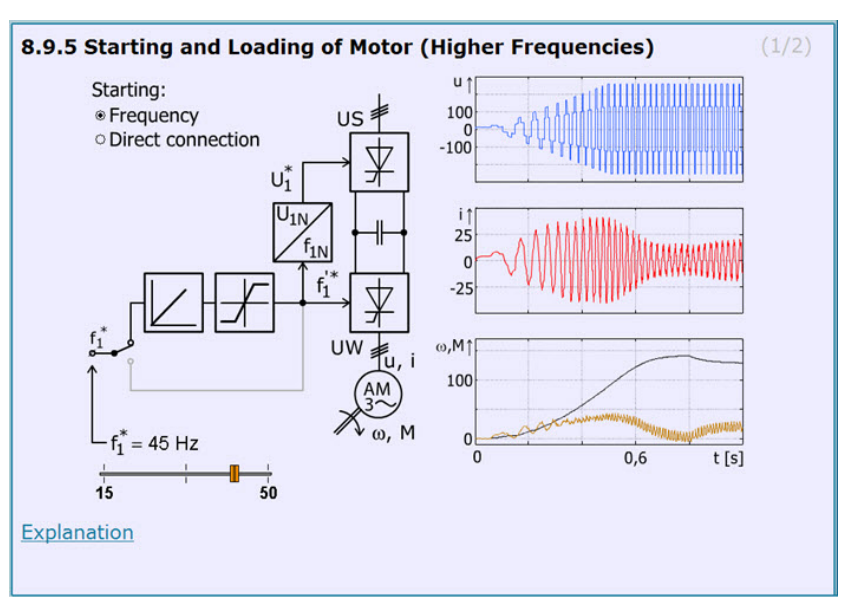

Fig. 5. Experiments with AC drive behavior at its starting.

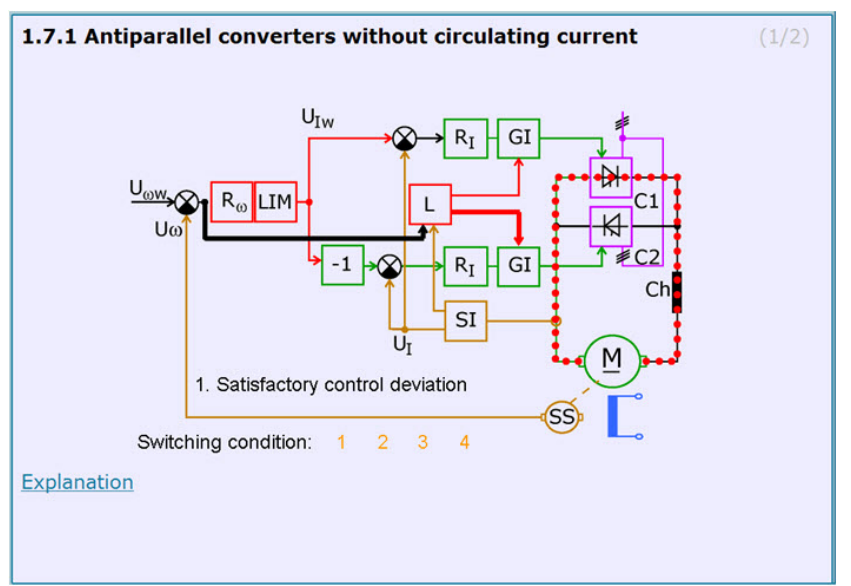

Fig. 6. Reversing the speed in antiparallel connected converters for the DC drive without circulating current.

the voltage-type frequency converter whose output was shown in Fig. 3(a).

The learner can investigate and compare influence of direct connection of the motor to the supply at the frequency starting with linearly increasing frequency and at preserving constant magnetic flow of the stator (V/f = const.). The oscillograms show courses of the motor phase voltage, phase current, speed and motor torque at starting and loading the motor after the speed reaches steady state. The frequency can be chosen by the slider in the range of 15 to $50 \mathrm{~Hz}$. Other screens show the motor behavior in range of very low frequencies where six-pulse supply from the converter causes unwanted motor behavior (stepping of the rotor) and the PWM modulation must be used.

The behavior of the motor in closed control loop is subject of presentation of the module on Controlled Drives [23]. It deals with linear control in time and frequency domains, with non-linear control in time domain and with control of AC drives. Except of unavoidable mathematical derivation at design of the drive controllers the module contains numerous block diagrams of various drive structures.

Fig. 6 shows a sequence at reversing speed of the DC motor in the drive with converters in anti-parallel connection which presents one of the very often drive structure used in industry.

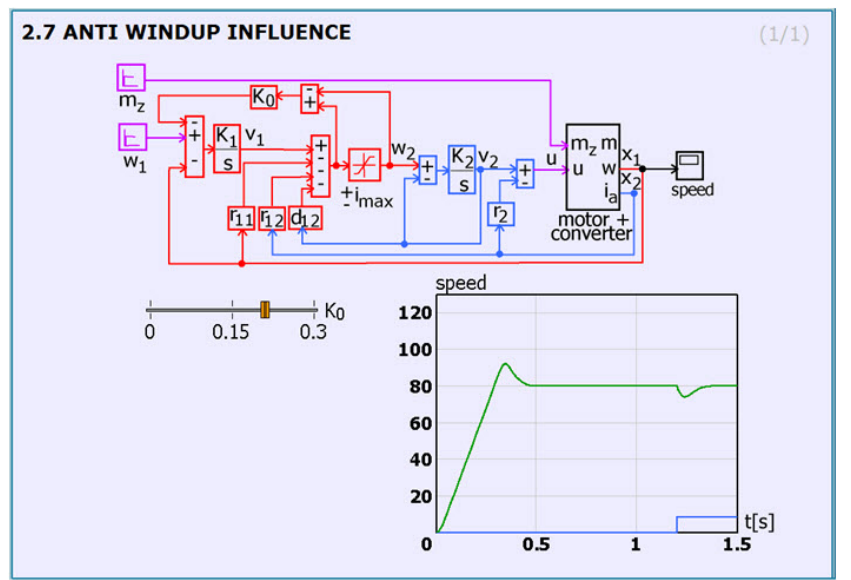

Fig. 7. Elimination of overshoot by an anti windup connection.

In order to avoid any short-circuit at reversing the speed, only one converter can be in conduction state. To ensure this, the switching-over is realized in 4 steps after satisfying conditions that are followed and evaluated by the logic block L. The explanation starts from the time instant when the converter $\mathrm{C} 1$ is operating as a rectifier and $\mathrm{C} 2$ is blocked. After the speed decreases, the speed reference polarity is getting to be negative what causes that the input of current controller becomes negative and current value quickly declines to zero. After overcoming the hysteresis range in the logic L, it starts to prepare the switching over (the first condition). When the current sensor will announce currentless state (the second condition) the logic blocks the first converter $\mathrm{C} 1$ and after a safety pause of $5 \mathrm{~ms}$ (third condition) there is cancelled blocking of the second converter $\mathrm{C} 2$. Its voltage decreases under motor induced voltage value and regenerative braking follows. Speed sensor SS changes its polarity at zero speed and start in opposite direction follows.

State of the circuit in each from the switching condition can be followed independently, in individual steps (Fig. 6).

Principle of influence of Anti-Reset-Windup (ARW) connection for elimination an overshoot at the output of a controller with an integrating character can be followed in Fig. 7.

At explaining complicated systems which are typical for the $3^{\text {rd }}$ and $4^{\text {th }}$ groups of the modules (converters, controlled electrical drives, electro-mechanical subsystems, etc.), we advantageously decompose them into subsystems. Interconnection of subsystems considerably improved legibility of the system from the first glance.

The following example of a speed-controlled drive with Switched Reluctance Motor (SRM) gives a good overview of the method. The screen with block diagram of the drive is shown in Fig. 8 that consists of several subsystems.

Mathematical description of the SRM is enough complicated due to the nonlinear and two-dimensional character of the motor where its phase inductances is varying both with the phase current and rotor position:

$$
U=R i+\frac{\partial \Psi(i, \Theta)}{\partial i} \frac{d i}{d t}+\frac{\partial \Psi(i, \Theta)}{\partial \Theta} \frac{d \Theta}{d t}
$$




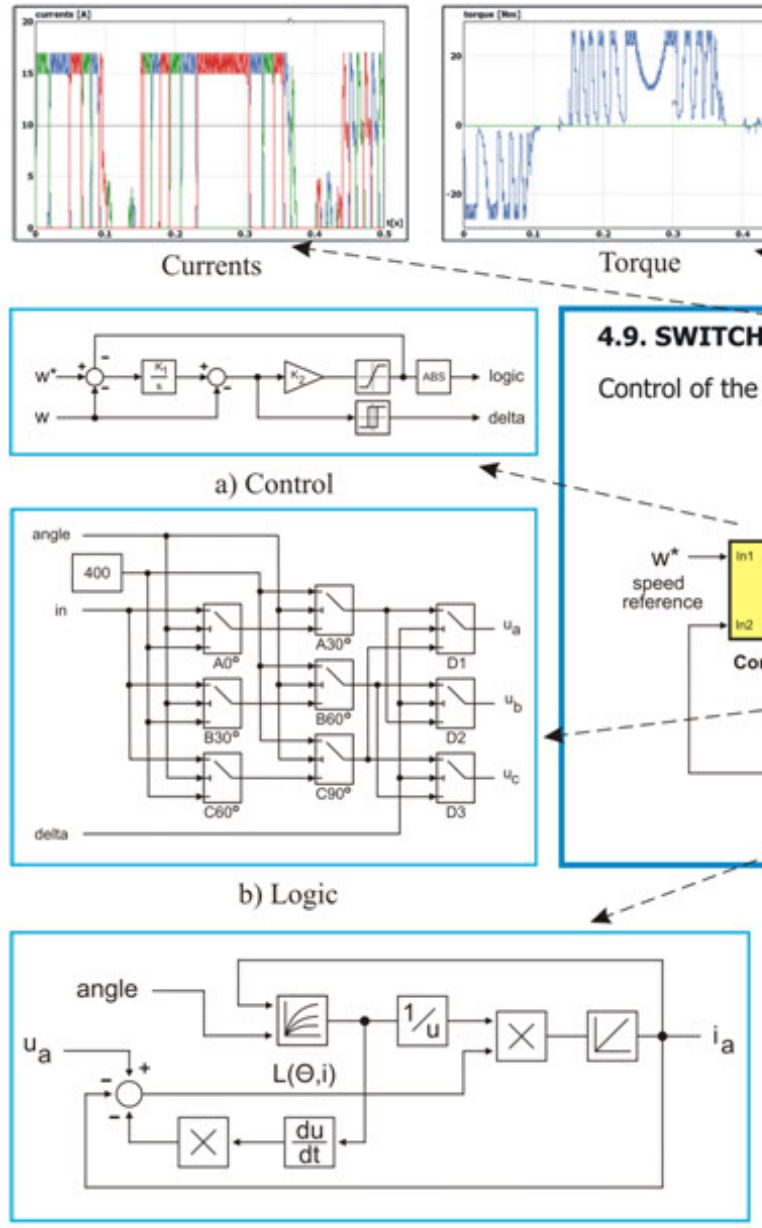

c) Windings

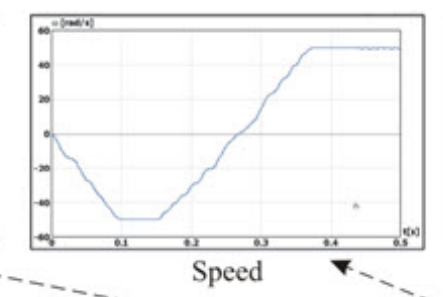

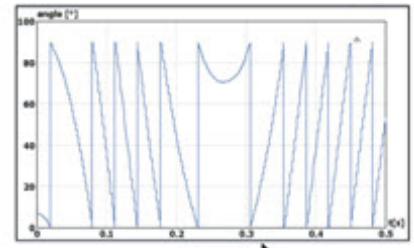

Angle
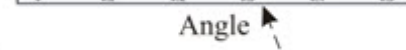

\section{OR}
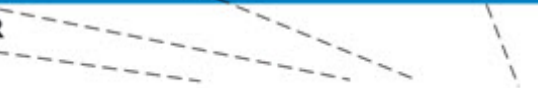

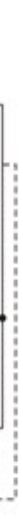

Switched Reluctance Motor

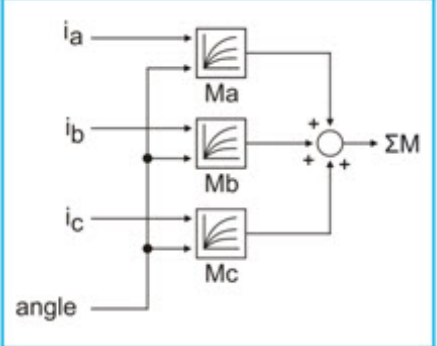

d) Torque

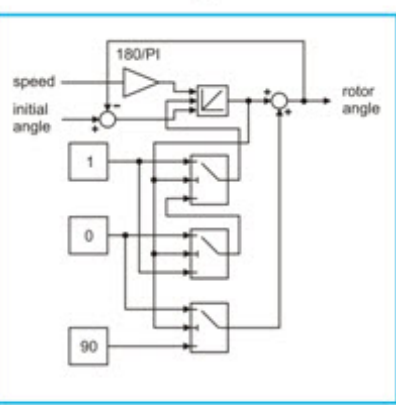

e) Rotor angle

Fig. 8. The screen with a controlled SRM and linked subscreens with subsystems and time responses (the subscreen appear after clicking on the block).

$$
M(i, \Theta)=\frac{\partial}{\partial \Theta} \int_{0}^{i} \Psi(i, \Theta) d t .
$$

For the SRM block diagram it is necessary to measure functions of inductance $L(i, \Theta)$ and torque $M(i, \Theta)$. One subsystem of the motor presents windings (subsystem $c$ in Fig. 9(a)) where the winding of each phase is modeled by the non-linear equation

$$
i=\int \frac{1}{L(\Theta, i)}\left(u-R i-\frac{\partial L(\Theta, i)}{\partial t} i\right) d t
$$

The subsystem for the motor torque calculation (subsystem $d$ in Fig. 8) is derived from the following equation:

$$
M=\frac{N_{m} p}{2 \Phi \pi} \iint \frac{\partial \Psi(i, \Theta)}{\partial \Theta} d i d \Theta .
$$

Further subsystem $(e)$ of the SRM calculates instantaneous angle of the rotor from its known angular speed. For the SRM with pole ratio $6 / 4$ the distribution of converter pulses repeats after every $90^{\circ}$ what means that it is satisfactory to determine the model for this interval only. The motor model is completed by the converter which is modeled by hysteresis block and logic (subsystem $b$ ) and by the controller (subsystem $a$ ).

\section{E. Group of Modules on CAD and Applied SW in Electrical Engineering}

This group deals with the issues such as automatic design (CAD), simulation and modeling. The following modules were designed:

5.1 Automatic Design and Projecting in Electrical Engineering

5.2 Simulation of Power Electronics

5.3 FEM in CAD of Electromechanical and Electromagnetic Devices

The main issues captured can be summarized as:

- explanation of different models,

- simulation techniques and numerical calculation,

- different design and analysis techniques.

The next examples come from the module 5.2 Simulation of Power Electronics. Fig. 9a shows comparison of different integration methods. This knowledge is essential for proper and effective simulation. The integration step can be changed by moving the slide on the interactive animation and the accuracy is shown for each method. At the same time the 


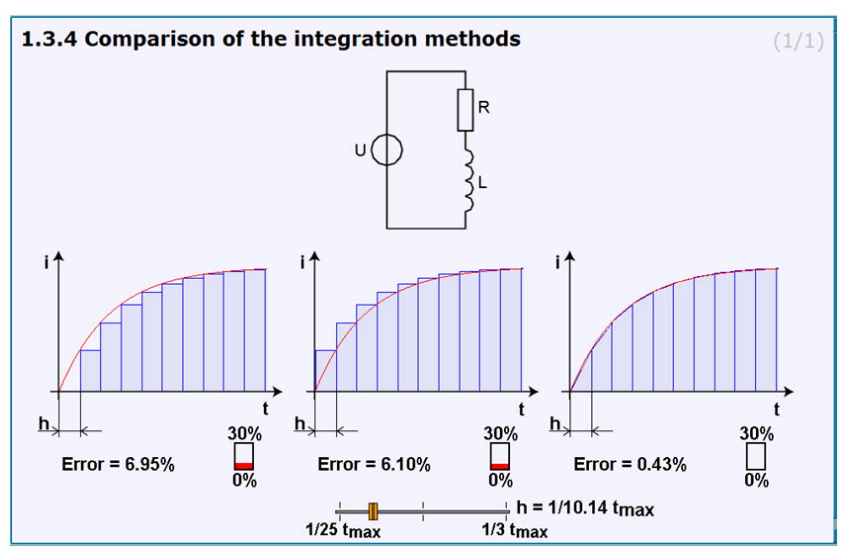

(a)

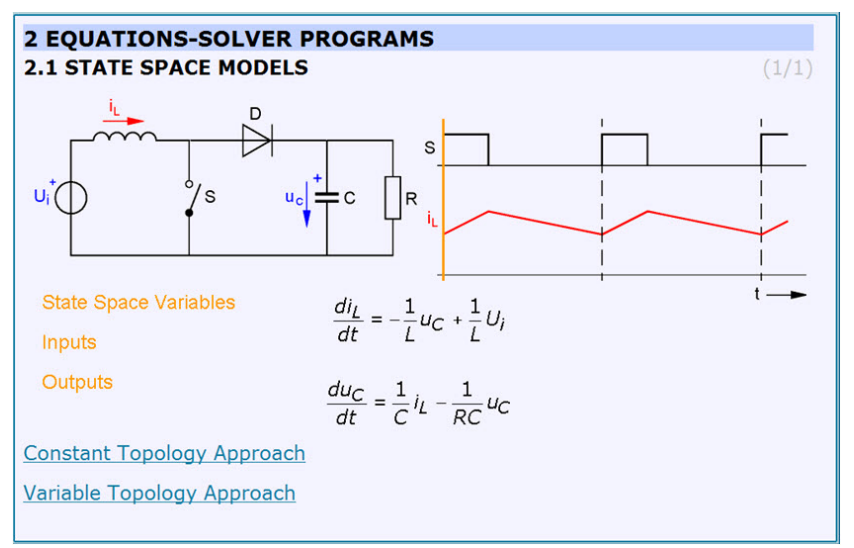

(b)

Fig. 9. (a) Comparison of integration methods; (b) state space model chapter.

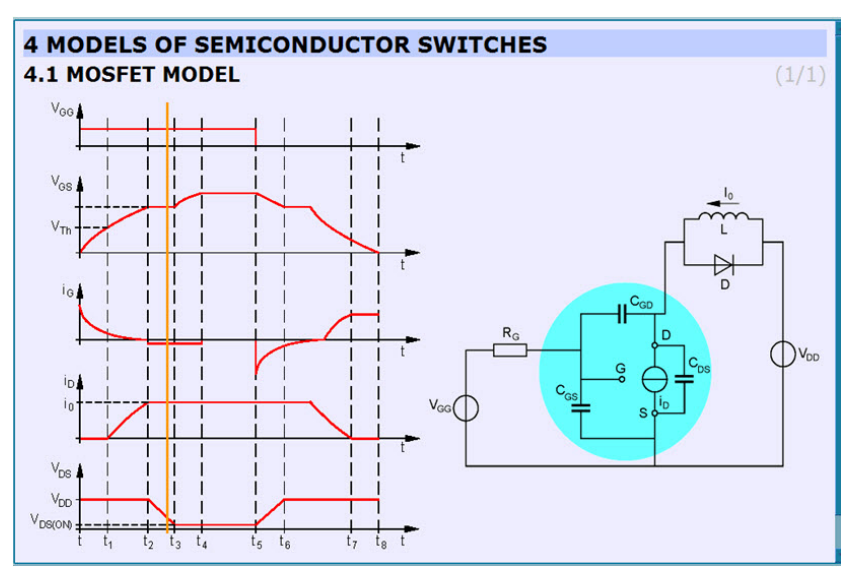

Fig. 10. Models of semiconductor switches.

accuracy is shown graphically too. In the next example a state space model of a power converter is explained (Fig. 9(b)). The equations describing the circuit are changing according the switching state.

Following the top down approach a model of semiconductor switch with waveforms and schematic per switching instant is shown (Fig. 10).

Initially $\left(t_{0}\right)$ the device is off and the load current $I_{0}$ flows through $\mathrm{D}$. The schematic is changing according to the switch state. The turn on characteristics are divided in four intervals and accordingly to four equivalent circuits. By sliding the orange bar the switching state is changed. In the interval shown $\left(t_{2}-t_{3}\right)$ the diode turns off the load current $\mathrm{I} 0$ and drain current starts linearly discharging the drain to source capacitance. Similarly the turn off characteristics of the MOSFET are divided into three time intervals with equivalent circuit for each interval.

\section{CONCLUSIONS}

In the paper we present basic problems that an e-Learning module developer meets when designing a module from field of power electronics and/or electrical drives having interactive features. The module developer has not only to be familiar with learning procedures of the student - to foresight his reactions and learning procedures, but he must possess considerable imagination, innovation in utilization and discover new advances for explanation the phenomena and last but not least, to have an artistic-like feeling for the final product layout of the screens.

Based on a carefully elaborated plan and philosophy of the interactive multimedia modules we have developed a set of 18 modules covering five main fields of electrical engineering. In the project of such large extent, the most important is the task of the principal philosophy of the modules whose fundamental principles are described in the paper. The developed modules feature by unified environment and thanks to division in the main and secondary screens they are suitable both for lectures and for self-study (for web-based distant learning as well), including in-detail explanations for repetition and self-study. This is realized by introducing a hierarchy of the screens: main screens and secondary screens (sub-screens) which are called by hypertext links from the main screens. The modules also have other features like: hypertext references, list of used symbols, keywords, contents, questions for knowledge testing, etc. A simple and friendly user environment enables easy to manage the module. The modules were prepared using the Macromedia Director [25] and were compiled using Macromedia Dreamweaver. The whole set of the modules will be available in English and also in different languages.

In the modules we have introduced a unified system of colors that facilitates orientation in the module. E.g., the orange color means an action, i.e., after clicking on the orange block or the orange line, the action is activated. This is the reason why the block of subsystems and scopes on the screen (Fig. 8) are marked by orange color. After clicking by mouse on the block the user sees details. Similarly, the learner sees oscillograms of the motor typical variables (currents, torque, speed, and angle).

Except for the animations, the modules contain built-in simulation schemes allowing change of parameters while giving direct response on the results. This feature enables to perform small experiments, to evaluate influence of the variable parameter to system behavior and leads to increase of their utilization. The last development in the field also comprises direct involvement of the program for digital simulation into the user's environment in order to enable the learner to change the most important parameters of the system and movie 
presentation of real systems. The modules are available at http://andromeda.fei.tuke.sk, part about e-learning modules.

\section{ACKNOWLEDGEMENT}

The author acknowledge the financial support (contract No CZ 134009) to the project ,Interactive and Unified E-Based Education and Training in Electrical Engineering", INETELE, supported by the EU in framework of Leonardo da Vinci II program and to The Scientific Grant Agency of The Ministry of Education of Slovak Republic under the contract VEGA No. 1/0099/09.

\section{REFERENCES}

[1] U. Drofenik, J. W. Kolar, P. J. van Duijsen, P. Bauer, "New web-based interactive e-learning in power electronics and electrical machines," in Conf. Record of the 2001 IEEE Industry Applications Conf. 36th IAS Annual Meeting, Vol. 3, pp. 1858 - 1865, Sep./Oct. 2001.

[2] U. Drofenik, J. W. Kolar, "Interactive power electronics seminar (iPES) - a web-based introductory power electronics course employing javaapplets," in Proceedings of the 33rd IEEE PESC, Vol. 2, pp. 443 - 448, Jun. 2002.

[3] V. Fedak, P. Bauer, V. Hajek, H. Weiss, B. Davat, S. Manias, I. Nagy, P. Korondi, R. Miksiewicz, P- J. van Duijsen, P. Smékal, "Interactive e-learning in electrical engineering. EDPE'03," in Proceedings of Int. Conf. on Electrical Drives and Power Electronic, EDPE 2003, pp. 368373, 24-26 Sep. 2003.

[4] P. Bauer, V. Fedák, "Educational visualization of different aspects for power circuits and electrical drives," in Proceedings of 11th Int. Power Electronics and Motion Control Conf., EPE-PEMC'2004, Sep. 2004.

[5] P. Bauer, V. Fedak, "Implementation of e-learning platform for electrical engineering," in. Proc. of Computer Based Learning in Science Int. Conf., CBLIS 2005, Jul. 2005.

[6] A. Ruplis, E. Priednieks, O. Krievs, O., "New learning tools for the course on electrical engineering and electronics," in Proceedings of EPEPEMC, 2004.

[7] K. W. E. Cheng, Y. Lu, "Development of an electronic book for Power Electronics, Machine and Drives based on the Multilingual and ProblemBased Learning Techniques," in Proceedings of EPE-PEMC, 2004.

[8] Shadi Harb, Kalaid Kalaldiah, Ahmad Harb and Issa Batarseh - Interactive JAVA Applets for Power Electronics E-Learning http://www.apecor.com/Publications/003.PDF, Apr. 10th 2010.

[9] C. R. Sullivan, "Three dimensional animations of visualize voltage and current," in Proceedings of IEEE PESC 2003, pp.466-473, Jun. 2003 http://engineering.dartmouth.edu/other/3Dcircuits, Apr. 10th 2010.

[10] J. Hamar, H. Funato, S. Ogasawara, "E-learning in power electronics: the state of the art," in Proceedings of IPEC 05, Apr. 2005.

[11] H. Weiss, A., Schmidhofer, A., Schmid, et al, "Animated and interactive e-learning concept and realization," in Proceedings of IASTED, Int. Conf. on Web-Based Education, WBE, 2004.

[12] S. Sheng, P. Liou, H. Soelaeman, P. Leung, J. Kang, "A distance learning power electronics laboratory," in Proceedings of American Society for Eng. Education (ASEE) Annual Conf, Jun./Jul. 1998.

[13] Monteil C., Metz, M., "Visualisation de courbes avec variation paramétrique active sous EXCE," 3EI, $\mathrm{n}^{\text {circ }} 35$, "L'outil informatique dans l'enseignement," pp.23-26, Dec. 2003 - See also (in French) http://www.inptoulouse.fr/excel-interactif, Apr. 10th 2010.

[14] M. P. Kazmierkowsky, R. Bracha, "Virtual laboratory of power electronics pulse width modulation in three-phase converters," in Proceedings of Int. Conf. EPE-PEMC'2004, Sep. 2004.

[15] C. Fernández, O. García, J. A. Cobos, J. Uceda, "Self learning laboratory set up for teaching power electronics combining simulations and measurement," in Proceedings of Int. Conf. EPE-PEMC'2002, 2002.

[16] I. Humar, M. Pustisek, J. Bester, "Developing dynamic educational material with integrated mathematical notation for web-based e-learning system," in Proceedings of 33rd ASEE/IEEE Frontiers in Education Conf., pp. T3F-19 - T3F - 24, Nov. 2003.
[17] A. McGettrick, M. D. Theys, D. L. Soldan, P. K Srimani, "Computer engineering curriculum in the new millennium," IEEE Transaction on Education, Vol. 46, No. 4, Nov. 2003.

[18] H. M. Todorovic, L. Palma, P. Enjeti, "Development of new webbased materials to teach power electronics courses," in Proceedings of PEEW/PESC, Jun. 2005.

[19] S. Harb, K. Kalaldeh, A. Harb, I. Batarseh, "Interactive JAVA applets for power electronics e-learning," in Proceedings of PEEW/PESC 2005, Jun. 2005.

[20] C. A. Canesin, F. A. S. Gonçalves, "Educational JAVA applets get in power electronics labs," in Proceedings of PEEW/PESC 2006, Jun. 2005.

[21] V. Fedák, M. Kostelny, J. Kanuch, "Interactive e-learning tool for electrical machines," in Proceedings of 4th Int. Conf. on Emerging Telecommunications Technologies and Applications, ICETA 2005, pp. $263-266,2005$.

[22] A. Boboń, J. Kudła, R. Miksiewicz, "E-learning based teaching of alternating current electrical machines," in Proceedings of Int. Conf. on Engineering Education, ICEE 2005, 2005.

[23] V. Fedák, M. Repiscak, L. Zboray, "Design and implementation of elearning tool for courses on electrical drives," in Proceedings of Int. Conf. on Electrical Drives and Power Electronics, EDPE 2005, CD ROM - E05-115, 2005.

[24] Z. Ferkova, L. Zboray, "Sensorless control of the switched reluctance motor," in Proceedings of the Electrical Drives and Power Electronics Int. Conf., EDPE '03, The High Tatras, pp. 113 - 116, Sep. 2003.

[25] Macromedia Director Downloads www.adobe.com/products/director/download/, Jul. 31st, 2010.

[26] CASPOC - Power Electronics and Electrical Drives Modeling and Simulation Software - www.simulation-research.com, Jul. 31st, 2010.

[27] J. Dudrik, P. Bauer, "New methods in teaching power electronics converters and devices," in Int. Journal Engineering Education, (IJEE), pp.1040-1048. Vol. 24, No 5, 2008.

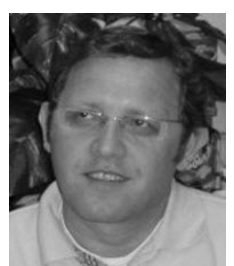

Pavol Bauer received his Masters in Electrical Engineering at the Technical University of Kosice ('85), Ph.D. from Delft University of Technology ('95) and title Prof. from the Brno University of Technology (2008). Since 1990 he is with Delft University of Technology, teaching Power Electronics and Electrical Drives. P. Bauer published over 50 journal and 200 conference papers in his field, he is an author or coauthor of 6 books, he holds an international patent. $\mathrm{He}$ organized several tutorials at the international conferences. He has participated in several Leonardo da Vinci EU projects as project partner (ELINA, INETELE) and coordinator (PEMCWebLab.com). He is a Senior Member of the IEEE, Chairman of Benelux IEEE Joint Industry Applications Society, Power Electronics and Power Engineering Society chapter, member of the EPE-PEMC council, EPE member and also member of international steering committee at numerous conferences.

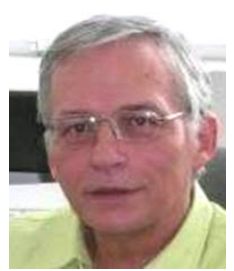

Viliam Fedák graduated from the Technical University of Kosice, Slovakia (1972). He works as Associate Professor at the Dept. of Electrical Engineering and Mechatronics, TU Kosice. He teaches subjects on Electrical Drives, Dynamics and Modeling of Electromechanical Systems, System Identification. He was coordinator of several EU projects on education (ELINA, eEDUSER, INETELE, ...) and partner of many others. His publications are mainly from field of control of electrical drives, mechatronic systems, and education. He is EPE-PEMC Council member (Budapest). Since 1994 he is the chairman of EDPE (Electrical Drives and Power Electronics) international conferences held alternatively in Slovakia and Croatia, also was the general chairman of EPE-PEMC 2000-Kosice and he has been steering committee member of numerous international conferences in the field of his specialization and education, too. 